\title{
Price and reimbursement for orphan medicines and managed entry agreements: does Italy need a framework?
}

\author{
Claudio Jommi ${ }^{1}$, Antonio Addis ${ }^{2}$, Nello Martini ${ }^{3}$, Elena Nicod ${ }^{4,1}$, Marcello Pani ${ }^{5}$, Annalisa Scopinaro ${ }^{6}$, Sabine Vogler \\ ${ }^{1}$ Cergas SDA Bocconi School of Management, Milan - Italy \\ ${ }^{2}$ Department of Epidemiology, Regional Health Service (Regione Lazio) Member of the Scientific Technical Committee, Italian Medicines \\ Agency (AIFA), Rome - Italy \\ ${ }^{3}$ Fondazione ReS (Research and Health Foundation), Rome - Italy \\ ${ }^{4}$ Dolon Ltd, London - UK \\ ${ }^{5}$ Agostino Gemelli IRCCS University Hospital Foundation, Rome - Italy \\ ${ }^{6}$ UNIAMO (Italian Federation for Rare Diseases), Rome - Italy \\ ${ }^{7}$ WHO Collaborating Centre for Pharmaceutical Pricing and Reimbursement Policies, Austrian National Public Health Institute (GÖG), \\ Vienna - Austria
}

\begin{abstract}
This article illustrates a consensus opinion of an expert panel on the need and usefulness of a framework for price and reimbursement (P\&R) process and managed entry agreements (MEAs) for orphan medicines in Italy.

This opinion was gathered in three rounds: an introductory document was sent to the panel and discussed during a recorded online meeting. A second document was sent to the panel for their review. In the third step the final document was validated. Members of the expert panel are the authors of the article.

The panel agreed that Italy does not need a specific value framework for orphan medicines, driving the P\&R process. Rather, a more structured value framework for all medicines tailored to the specific drugs can be useful. For orphan drugs, the panel advocated for a multidisciplinary approach and the contribution of different stakeholders to value assessment, and acknowledged the importance of addressing, more than for other drugs, unmet needs, equity issues and societal value. The panel raised the need of increasing the importance of patient-reported outcomes. Experts, acknowledging the growing criticisms in implementation of outcome-based agreements in Italy, expressed their position against their abandonment in favour of discounts only and supported orphan medicines as natural candidates for these agreements.

Finally, the panel made some recommendations on the appraisal process for orphan medicines, including an early discussion on the uncertainty of the evidence generated and the adoption of a structured approach to identify the agreement, which better responds to the uncertainty.

Keywords: Italy, Managed entry agreements, Orphan medicines, Value framework
\end{abstract}

\section{Background}

Orphan drugs, targeting unmet needs and rare conditions, raise specific market access issues. Rarity may lead to "sub-standard" clinical evidence at the time of launch, when compared to more prevalent diseases. In fact, clinical trials include small population samples, the profile of recruited

Received: May 14, 2021

Accepted: July 27, 2021

Published online: August 5, 2021

Corresponding author:

Claudio Jommi

Cergas, Centro di Ricerche sulla Gestione

dell'Assistenza Sanitaria e Sociale

SDA Bocconi School of Management

Università Bocconi

Via Sarfatti 25

20136, Milano - Italy

claudio.jommi@unibocconi.it patients is heterogeneous (in terms of age, stage and severity of the disease) and robust evidence on the disease progression and on its burden on patients is often not available. Moreover, labelled comparators are absent and their offlabel use, if any, usually suffers from the inexistence of robust evidence (1-4).

Rarity may also be related to a potential lack of knowledge on the underlying physio-pathologic mechanisms involved in the disease, which has not received the same attention and investment as more prevalent diseases, not necessarily because the mechanisms themselves are more complex. When new medicines for rare diseases are available, the demonstration of their value may be based on specific surrogate outcomes. Evidence of the relationship with phenotypic or symptomatic dimensions of the disease must be established, together with their potential for modifying the course of the disease. This is not specific to rare disease, but frequent.

Orphan drug policies acknowledge the issue of the lack of scientific and clinical evidence in this area, since they aim at incentivizing companies to invest in research and 
development (R\&D) for rare diseases, in order to correct inequalities in access to effective treatments compared to diseases that are more prevalent. This also leads to a higher acceptance of "sub-standard" evidence at the time of registration, than for other disease areas. Indeed, the explicit goal is to provide patients with effective treatments, but also to trigger further research once the treatment is on the market, either way through basic and clinical research. Nevertheless, this allows market access institutions (payers) that assess and appraise new medicines, to decide on price and reimbursement $(P \& R)$, with the actual responsibility to provide for a reasonable value framework that incorporates the uncertainty on the 'value'.

Responses to these challenges have been a critical review of value frameworks and value-based pricing for orphan medicines as well as the introduction of managed entry agreements (MEAs) to manage the risk of reimbursement related to uncertainty.

As for the first topic, some papers advocated for the identification of a specific value framework for orphan medicines. For example, the ORPH-VAL Group (1) recommended:

- to implement a multidimensional framework that looks beyond the value of the medicine and incorporates other considerations, such as societal preferences, rarity of the disease, unmet needs and sustainability of innovation in rare diseases;

- that if access does not rely on a multidimensional approach, but on incremental cost-effectiveness ratio (ICER) thresholds, this should be modulated to reflect all specificities of rare diseases, including rarity, unmet therapeutic needs and societal preferences;

- to inform price negotiation, among other elements, by considering the magnitude of the product value in light of price-value precedents for other specialized technologies and medicines;

- to involve rare disease expertise, including both the health care professionals' and patients' perspectives.

Other authors suggested a more operational framework. For example, Hughes-Wilson and others (5) proposed specific domains as drivers of the price setting. Some domains are value-based, including disease severity, level of unmet need, quality of the evidence and level of the effectiveness uncertainty; others refer to a trade-off between unit price and volumes and include the prevalence and the use of medicines for one or many indications; still others consist of a cost-plus pricing approach (i.e. manufacturing complexity). Berdud and others (6) estimated a modular threshold on ICER, based on the one used for medicines in England, that depends on the expected volumes and their impact on return of investments, calculated on the ground of orphan-specific R\&D cost estimates.

In Italy, there is no specific framework for the assessment of orphan medicines, and the P\&R process for all drugs has been recently revised. The guidelines for the P\&R dossier (7) explicitly mention orphan medicines as possible targets for pharmaco-economic evidence. These guidelines have incorporated the framework used for the appraisal of the innovativeness status of medicines, which relies - according to Italian Medicines Agency (AIFA) - on three criteria: the unmet need, the added therapeutic value and the quality of the evidence, based on the GRADE system (8). For orphan medicines, a low quality of the evidence at market launch, according to the GRADE system, may be considered acceptable, when the other two criteria (the unmet need and the added therapeutic value) are high, or at least moderate.

In Italy, in 2019 orphan drugs accounted for $6.6 \%$ of total expenditure for reimbursed drugs. Among the different therapeutic classes considered orphan, medicines for rare tumours accounted for more than $50 \%$ of total spending, followed by those for neurological disorders (7.5\%, of which the enzyme replacement therapy determined the highest mean cost per patient - €260k), genetic diseases (7.4\%) and idiopathic pulmonary fibrosis (7.1\%) (9).

MEAs are broadly defined as an arrangement between a manufacturer and payer/provider that enables access to (coverage/reimbursement of) a health technology subject to specified conditions (10). The first component of this uncertainty consists of the switch from clinical trials' efficacy/safety evidence to effectiveness/tolerance observed in daily practice. The payer does not want to pay for uncertain health benefits per patient and/or an excess of severe adverse events, at least at the initial price. The second component is focused on effectiveness/tolerance. Specifically, the observed sustainability of the expected benefit/risk ratio through time could potentially translate into a long duration of treatment. The third component is related to the size of the eligible population, both prevalent and incident. The existence of an effective treatment can increase the size of the prevalent population, because screening for the disease may be technically improved and intensified. Moreover, if patients receive a sustained benefit, the size of the prevalent population under treatment will increase through time at least at the rate of incidence.

MEAs are traditionally classified into four classes, according to two possible sets of contingencies (10-12) (Tab. I):

- financial-based agreements, which allow payers to share with the industry the post-marketing budget impact of new drugs vs outcome (or performance)-based agreements, that link payers' commitment to the actual impact of the drugs on health;

- patient-level agreements, when the financial/outcome effect is measured on each single patient (e.g. patient cost cap for financial-based agreement and performancelinked reimbursement), vs population-level agreements that consist of an effect measured on the whole target population (e.g. coverage with evidence development and price-volume agreements).

Table I - Managed entry agreements

\begin{tabular}{lll}
\hline & Population Level & Patient Level \\
\hline $\begin{array}{l}\text { Financial } \\
\text { Based }\end{array}$ & $\begin{array}{l}\text { Price/volume agreement } \\
\text { Sales cap }\end{array}$ & $\begin{array}{l}\text { Patient utilization } \\
\text { (or cost) cap } \\
\text { Free/discounted } \\
\text { treatment initiation }\end{array}$ \\
$\begin{array}{lll}\text { Outcome } \\
\text { Based }\end{array}$ & $\begin{array}{l}\text { Coverage with evidence } \\
\text { development }\end{array}$ & $\begin{array}{l}\text { Performance-linked } \\
\text { reimbursement }\end{array}$ \\
\hline
\end{tabular}

Source: Adapted from (10-12). 
Among the above uncertainty components, the first and potentially the second ones are eligible to outcome-based agreements, since the sustainability of the benefit derived from the treatment through time is a proxy of its actual effectiveness. The second component can also be amenable to financial agreements, since duration of treatment is easily observable and has a direct impact on budget. The third component is manageable through financial agreements. For example, the uncertainty may result from incomplete knowledge of the prevalence of the disease at the time of launch, and of the size of the eligible population. It may also be the result of the expansion of this prevalence related to the existence of an effective treatment. The payer considers this case as a market success for the company and will expect to share its benefits because of the higher volumes than expected.

MEAs in principle can bring important advantages for the industry and the payers (13). Pharmaceutical companies take advantage of MEAs to achieve the drug coverage and to improve their public image, their position within the competitive arena and the relationships with payers. Moreover, local affiliates of pharmaceutical companies use MEAs to meet price cut requirements by payers, leaving list prices within the price corridor set by their parent companies. These corridors avoid cross-country high differences in the list prices. Thus, they ensure that neither payer refer to the lower net prices in cross-referencing nor parallel traders taking advantage of the system. MEAs help payers to manage the financial risk related to uncertain clinical benefits. Through MEAs, payers may also guarantee patients accessing new drugs, while ensuring an efficient allocation and the appropriate use of resources. In this way, they can manage the pressure from patient associations, politicians and media. MEAs could also allow a flexible management of multiple indications, providing for indication-based agreements for the same drug. If the prescription per indication is traced, MEAs can be set per indication, depending on the relevant drugs' value.

However, some contributions have highlighted possible drawbacks of these agreements, including: a general concern on the driver, which seems to be more affordability than managing uncertainty $(14,15)$; the issue of poor enforcement for coverage with an evidence-development-type contract: in fact, the advice to discontinue reimbursement for medicines with unfavourable post-marketing evidence was not applied (16); important transaction costs in charge of both parties and the administrative burden on health care providers (17); the expectation that if a MEA is signed with many payers, companies may ask for higher list prices (18).

\section{Objective and methods}

This document reports the discussion and the consensus reached by an expert panel on whether:

- a specific value-based framework for orphan medicines is needed for P\&R negotiation;

- a more structured approach to outcome-based MEA may support their use in the future and how.

The panel is composed by the authors of this 'Point of View' article. They represent the stakeholders involved in the topics under discussion (i.e. regulatory authorities, regional representatives, hospital pharmacists, patients' associations) and international experts. The selection of experts relied on the interest in their participation (sample of convenience) (19).

Panellist were invited to participate on the 9 November 2020. The discussion meeting was carried out on 15 December 2020 and lasted 2.5 hours ( 3 pm-5.30 pm). It was managed virtually and recorded. The panel was coordinated by CERGAS (Centre for Research on Health and Social Care Management) researchers.

Before the meeting, the panellists received a document with a description of the background (first paragraph of this article), the objective of the meeting, the meeting format and list of participants, the agenda, the follow-up actions and the project sponsors. More specifically, panellists were informed that the objectives of the Panel were discussing:

- value-based framework for orphan medicines, that is, whether a specific value framework for access issues $(P \& R)$ is needed or the existing value framework adopted in Italy is sufficiently broad to capture the specific characteristics of orphan medicines;

- MEAs applied to orphan medicines, that is, whether (i) outcome- and/or financial-based MEAs are still a useful option to manage uncertainty (or a hidden discount on list prices is preferable, if affordability is the main issue), (ii) a general framework can be created to identify the most appropriate mix of value-based and financial agreements, given the characteristics of the treatment.

During the meeting, the panel was introduced to the concept of using a more structured approach to facilitate the discussion and design of MEAs between manufacturers and payers. Such an approach was not supposed to increase the complexity of the agreements, but rather to facilitate a structured dialogue between manufacturers and payers, in order to agree on the need for a MEA and to implement it in an effective, feasible and acceptable manner. This would involve identifying which products are candidates for a MEA, identifying, agreeing and prioritizing the risks that should be addressed, and agreeing on suitable terms to address this risk that are satisfactory for both sides.

The minutes of the meeting were shared with the panel for a feedback on 12 January 2021 with a first draft of the consensus document (first round). A revised second document was sent on 1 March to all panellists (second round). The third version of the document was sent on 15 April and all authors agreed on this final version (third round).

The following paragraphs report the consensus document of the panel.

\section{Results (consensus document)}

\section{$P \& R$ framework for orphan medicines}

- On the one hand orphan medicines have some commonalties that could make them eligible for a common assessment and appraisal framework:

o although the target population is expected to be small, in many cases the uncertainty on the dimension 
of the target population leads the payers to rely on estimates provided by the marketing authorization holder and coming from the market research, expert panels, etc.;

- data on the relevant clinical pathways are often scarce;

o the still very frequent unmet needs.

- On the other side orphan medicines are heterogeneous for many aspects:

o the panel acknowledged that, even if the target populations for orphan indications are small, orphan medicines can have an overall major impact in terms of patients' clinical conditions and of value: however, their actual therapeutic value is very diverse, ranging from a limited impact to a curative effect;

- orphan drugs can have other non-orphan indications: the total yearly spending for medicines with also an indication for rare tumours ranges from $€ 80$ to 200 million in Italy.

- Due to differences across orphan medicines, the panel agreed that there is the need of a value framework for medicines in general. It is needed to adapt the general framework to each specific (orphan and non-orphan) drug category, but not to apply specific framework for them. For example, the panel agreed that assessment and appraisal of orphan medicines require, even more than other drugs, a multidisciplinary approach and the contribution of different stakeholders. The latter are very important to provide insights into the societal value and priority setting.

- As far as the general value framework (list of framework domains and their relevance) is concerned, the panel suggested:

- to make value framework more structured in general, using a holistic approach, in order to return a more transparent and reproducible access process;

o to maintain the necessary flexibility (e.g. avoiding rigid thresholds, if any, of the ICER).

- The panel acknowledged that the assessment of some domains is well established, for example, the level of disease severity, the added clinical value and the quality of the evidence. Other domains should be further explored, for example, the unmet need level, equity issues, societal value. For these domains, the contribution of policy-makers is important. The unmet need should also be investigated in terms of prioritization, considering that only 300 diseases out of 8,000 are covered by a treatment. Furthermore, the importance of some fields (e.g. the organizational impact) is increasing (e.g. for gene therapies). These areas of interest should be thoroughly considered in advance. Some domains should also be strengthened in the $P \& R$, for example, patient-reported outcome (PRO). Particularly, quality of life is very important for some rare diseases, but data in case of rare diseases are very often collected with difficulty. Among the domains mainly driven by the domestic environment, affordability is the most important one and should be addressed by avoiding:

- a silos approach, that is, considering at least the perspective of health payers;
- as far as possible, dedicated funds, unless they are aimed to secure access for medicines (e.g. funds for innovative medicines in Italy). This would refrain from multiple dedicated funds for medicines that are not consistent with an integrated approach and raise the risk of their inappropriate definition/management.

- Finally, despite P\&R relying on a value-based framework (and be value-driven), a better understanding of investments in R\&D in general and for orphan medicines in particular (and the return on these investments) is necessary $(6,20)$, especially when these drugs also have non-orphan indications.

\section{MEAs' structured approach}

- Orphan medicines are natural candidates for MEAs because of the high level of uncertainty on their effects, on the dimension of the target population and on the clinical pathway of the relevant disease. However, the panel discussed MEAs in general and not with a specific focus on orphan medicines. In this respect, the panel has also acknowledged that the IMPACT-HTA Project has created some tools to support use and implementation of an outcome-based MEA with a rare disease treatment (21).

- Panellists agreed on the importance of collecting realworld data, requiring a pre-defined protocol, and that MEAs without an appropriate data collection may be lost opportunities.

- The panel acknowledged the growing criticisms on (individual-based) outcome-based agreements in Italy, particularly the administrative burden, the absence of feedback information and the lack of transparency on the use of companies' payback.

- The panel expressed the view that these criticisms should not be the reason of abandoning the experience of outcome-based MEAs in favour of discounts and financialbased agreements only.

- However, before a MEA is implemented, the uncertainty should be faced, by a more structured early dialogue process between regulatory authorities, HTA (health technology assessment) authorities/payers and the industry. This dialogue should aim to discuss all available data, to be proactively managed by the payers (i.e. early dialogue should be promoted also by payers and not only by the industry), to terminate with a clear understanding of the 'residual' uncertainty and to address a better design of a MEA, if needed.

- In this perspective, the panel agreed that a more structured approach (i.e. a MEA framework) would be a good way to make the decision process more consistent, reproducible, transparent and equitable, also enhancing accountability of all parties involved. Further research to address this should be conducted. A framework may help to appropriately select the cases where MEAs are needed. Moreover, the duration of these agreements should be pre-specified.

- In addition to a framework, the panel agreed on the importance of:

- embedding MEAs into the P\&R process (MEAs should result in a $P \& R$ revision, once the necessary evidence has been collected); 
- providing for complete contracts, for example, enforcing decisions that should be taken based on the evidence collected. These decisions concern reimbursement, prices or other pre-defined actions (such as money-back transfer for non-respondents);

- designing MEAs in a way to maximize the usefulness of the information collected (through registries and/ or observational studies) and minimizing the administrative burden;

- providing feedback to health care professionals and, more in general, to the population.

- Despite MEAs being national agreements, the panel acknowledged that they can benefit from a broader collaboration at a European level, for example, through data collected by European registries.

- Finally, the panel expressed the opportunity to increase the transparency of the process that leads to MEAs. Even if the MEAs' detailed content is not fully transparent to the public (in order to avoid cross-reference pricing), other opportunities (e.g. sharing information on outcome-based agreements among authorities) could be explored.

\section{Conclusions}

This article reports a consensus document by an expert panel on whether a specific value-based framework for orphan medicines is needed for $P \& R$ negotiation and $a$ more structured approach to outcome-based MEA may support their use in the future and how. The panellists agreed that a structured value-based framework is important for medicines in general and should be adapted to each specific drug category. There was a general consensus that a specific value framework for orphan medicines is not needed. The panel acknowledged problems generated by outcome-based MEA but agreed that these problems should not imply that these agreements are totally abandoned. The panel has advocated for strengthening the dialogue between the industry and HTA agencies/payers, before P\&R is negotiated, to understand the real dimension of uncertainty and whether MEAs could address this uncertainty, to embed MEAs into the $P \& R$ process, to make the most of data collection and increase transparency, at least of the process leading to a MEA.

The main limitation of the study is the limited number of panellists. However, decision-makers (national medicines agency/regions/hospital pharmacies) were represented, together with other stakeholders (patient association) and experts on value framework, MEA, orphan drugs.

Despite this limitation, the consensus document provides valuable insights into the assessment, appraisal, $P \& R$ negotiation of orphan medicines and outcome-based MEAs, orphan medicine being a natural candidate for these agreements. This is particularly important for Italy, where the P\&R system for medicines has been recently reformed (7) and outcome-based MEAs have a long tradition but are increasingly being challenged.

The document provides general recommendations on value and MEA frameworks. The next step could be the design of a framework for MEAs that are particularly important for orphan medicines. This framework could address which products are candidates for a MEA, the risks to manage and the best way to address risks. The framework, being replicable, may have the advantage to speed up the decisions on P\&R with a satisfactory agreement for both sides.

\section{Disclosures}

Conflict of interest: The authors declare no conflict of interest. Financial support: Cergas SDA Bocconi has received an unconditioned grant from Alnylam Pharmaceuticals, Ultragenyx and Argenx to carry out this research. The expert panellists did not receive any financial contribution for their participation in the discussion and in the article.

\section{References}

1. Annemans L, Aymé S, Le Cam Y, et al. Recommendations from the European Working Group for Value Assessment and Funding Processes in Rare Diseases (ORPH-VAL). Orphanet J Rare Dis. 2017;12(1):50. CrossRef PubMed

2. Nicod E, Annemans L, Bucsics A, Lee A, Upadhyaya S, Facey K. HTA programme response to the challenges of dealing with orphan medicinal products: process evaluation in selected European countries. Health Policy. 2019;123(2):140-151. CrossRef PubMed

3. Nicod E. Why do health technology assessment coverage recommendations for the same drugs differ across settings? Applying a mixed methods framework to systematically compare orphan drug decisions in four European countries. Eur J Health Econ. 2017;18(6):715-730. CrossRef PubMed

4. Drummond MF. Challenges in the economic evaluation of orphan drugs. Eurohealth (Lond). 2008;14(2):16-17.

5. Hughes-Wilson W, Palma A, Schuurman A, Simoens S. Paying for the Orphan Drug System: break or bend? Is it time for a new evaluation system for payers in Europe to take account of new rare disease treatments? Orphanet J Rare Dis. 2012;7(1):74. CrossRef PubMed

6. Berdud $\mathrm{M}$, Drummond $\mathrm{M}$, Towse $\mathrm{A}$. Establishing a reasonable price for an orphan drug. Cost Eff Resour Alloc. 2020;18(1):31. CrossRef PubMed

7. Aifa. Linee guida per la compilazione del dossier a supporto della domanda di rimborsabilità e prezzo di un medicinale. Online Accessed April 2, 2021.

8. Galeone C, Bruzzi P, Jommi C. Key drivers of innovativeness appraisal for medicines: the Italian experience after the adoption of the new ranking system. BMJ Open. 2021;11(1):e041259. CrossRef PubMed

9. Osservatorio Nazionale sull'impiego dei medicinali. L'uso dei farmaci in Italia. Rapporto Nazionale Anno 2019. Roma: Agenzia Italiana del Farmaco; 2020. Online Accessed June 2021.

10. Dabbous M, Chachoua L, Caban A, Toumi M. Managed entry agreements: policy analysis from the European perspective. Value Health. 2020;23(4):425-433. CrossRef PubMed

11. Wenzl M, Chapman S. Performance-based managed entry agreements for new medicines in OECD countries and EU member states: How they work and possible improvements going forward. OECD Health Working Papers, No. 115. 2019. Paris, OECD Publishing. CrossRef Accessed April 2, 2021.

12. Morel T, Arickx F, Befrits $G$, et al. Reconciling uncertainty of costs and outcomes with the need for access to orphan medicinal products: a comparative study of managed entry agreements across seven European countries. Orphanet J Rare Dis. 2013;8(1):198. CrossRef PubMed 
13. Toumi M, Zard J, Abdallah IB, et al. An overview of market access agreements. In: Ethgen $O$, Staginnus $U$, eds. The future of health economics. London: Routledge 2016;78-108.

14. Neyt M, Gerkens S, San Miguel L, Vinck I, Thiry N, Cleemput I. An evaluation of managed entry agreements in Belgium: a system with threats and (high) potential if properly applied. Health Policy. 2020;124(9):959-964. CrossRef PubMed

15. Andersson E, Svensson J, Persson U, Lindgren P. Risk sharing in managed entry agreements - a review of the Swedish experience. Health Policy. 2020;124(4):404-410. CrossRef PubMed

16. Makady A, van Veelen A, de Boer A, Hillege $\mathrm{H}$, Klungel $\mathrm{OH}$, Goettsch W. Implementing managed entry agreements in practice: the Dutch reality check. Health Policy. 2019;123(3):267274. CrossRef PubMed

17. Jommi C. Managed entry agreements and high cost medicines (European perspective). In: Babar Z-U-D, ed. Equitable access to high-cost pharmaceuticals. London: Springer 2018;35-49. CrossRef

18. Gamba S, Pertile P, Vogler S. The impact of managed entry agreements on pharmaceutical prices. Health Econ. 2020; 29(S1)(suppl 1):47-62. CrossRef PubMed

19. Lohr S. Sampling: design and analysis. 2nd ed. Boston, MA: Brooks/Cole 2010.

20. Jayasundara K, Hollis A, Krahn M, Mamdani M, Hoch JS, Grootendorst P. Estimating the clinical cost of drug development for orphan versus non-orphan drugs. Orphanet J Rare Dis. 2019;14(1):12. CrossRef PubMed

21. Facey $\mathrm{K}$, Xoxi E, Kent E, et al. WP10 guidance to support consistent HTA appraisal for orphan medicinal products. D10.3 Guidance on use and implementation of outcome-based managed entry agreements for orphan medicinal products (Rare Disease Treatments) 12 May 2021. Online Accessed July 5, 2021. 